\title{
Role of Polyamines on Post-Harvest Fruit Quality and Storability
}

\author{
Divya Vani Vaka ${ }^{1 *}$, Kommana Pavani $^{2}$, Bharathi Nirujogi ${ }^{1}$ and \\ P. Vinaya Kumar Reddy ${ }^{3}$
}

${ }^{1}$ Department of Fruit Science, COH, Venkataramannagudem, Dr. Y. S. R. H. U, Andhra Pradesh, India

${ }^{2}$ Department of Horticulture, MSSSoA, Centurion University of Technology and Management, Parlakhemundi, Odisha, India

${ }^{3}$ COH, Venkataramannagudem, Dr. Y. S. R. H.U, Andhra Pradesh, India

*Corresponding author

\begin{tabular}{|c|c|}
\hline & A B S T R A C T \\
\hline $\begin{array}{l}\text { Ke y w o r d s } \\
\text { International trade, } \\
\text { Storage life, Shelf } \\
\text { life extension, } \\
\text { Spermidine (spd) }\end{array}$ & $\begin{array}{l}\text { As most of the fruits are highly perishable, short shelf life remains one of the major } \\
\text { impediments in the market and to increasing international trade, despite several research } \\
\text { efforts in the past to extend its storage life. A suitable method for shelf life extension, } \\
\text { which avoids detrimental effects on quality of fruit, would be beneficial for both the } \\
\text { consumer and the producer. One such strategy is use of postharvest treatments with } \\
\text { polyamines. Polyamines (PAs) are biological compounds of low molecular weight with }\end{array}$ \\
\hline Article Info & The most common PAs are putrescine (Put), spermidine (Spd) and spermine (Spm). \\
\hline $\begin{array}{l}\text { Accepted: } \\
26 \text { May } 2020 \\
\text { Available Online: } \\
10 \text { June } 2020\end{array}$ & $\begin{array}{l}\text { Polyamines (Spm, Spd, Put) and ethylene production are interrelated, since they share a } \\
\text { common precursor (SAM). Therefore, there is a possibility that polyamines may regulate } \\
\text { the process of fruit ripening and storage. The present paper reviews the effect of } \\
\text { exogenous polyamine application on improving the shelf life and quality of fruits during } \\
\text { storage. }\end{array}$ \\
\hline
\end{tabular}

\section{Introduction}

Polyamines (PAs) are small aliphatic amines that are ubiquitous in all plant cells. Polyamines interact with negatively charged macromolecules such as DNA, RNA, proteins, and phospholipids in such a way that they are involved in the regulation of the physical and chemical properties of membrane structure and functions of nucleic acids and modulation of enzyme activities (Galston and Sawhney 1990). In higher plants, PAs are mainly present in their free form. Putrescine (Put), spermidine (Spd), and spermine $(\mathrm{Spm})$ are the main PAs in plants, and they are involved in many biochemical and physiological processes such as cell division, cell elongation, flowering, fruit set and development, fruit ripening, and senescence (Evans and Malmberg, 1989; 
Galston and Kaur-Sawhney, 1990; Bouchereau et al., 1999). Many of these processes have direct implications on various aspects of postharvest biology of fruit crops including quality, storage life, senescence, chilling and other stresses and disease development (Valero et al., 2002)

The activities of PA metabolic enzymes and PAs contents change throughout the stages of plant growth. In whole plants, endogenous PAs and PA synthetase activity were found to be highest in the meristem and growing cells, and lowest in senescent tissues. As senescence occurs, the chlorophyll content gradually decreases, and the activities of ADC (arginine decarboxylase) and ODC (arginine decarboxylase) decrease, while the activities of PAO (polyamine oxidase) and hydrolases, such as ribonuclease and protease increase rapidly.

All of these changes can be inhibited by the application of exogenous PAs (Duan, 2000; Cai, 2009, Chen et al., 2019). However, one of the main aspects of the relationship between polyamines and fruit are those related to fruit ripening. Generally, there is an inverse relationship between the content of endogenous polyamines and ethylene production which is attributed to the fact that both share the common precursor S-adenosyl methionine (SAM) in their biosynthesis pathway (Valero and Serrano, 2010).

\section{Polyamine biosynthesis and regulation}

The biosynthesis and catabolism of the PAs are strictly controlled processes. In the case of plants, two pathways lead to Put formation from arginine. One involves the transformation from arginine to ornithine, which is catalyzed by the enzyme arginase. Then, ornithine is transformed to Put catalyzed by ornithine decarboxylase (ODC). The other route involves decarboxylation of arginine by arginine decarboxylase (ADC) to form agmatine and then agmatine is first converted by agmatine iminohydrolase to $\mathrm{N}$ carbamoylputrescine which is finally converted to Put by N-carbamoylputrescine amidohydrolase. The existence of two alternative routes (ADC/ODC) for the synthesis of Put could be explained by the differential compartmentalization of the two enzymes (ADC is chloroplast-localized and ODC is generally considered to be cytoplasmic), resulting in the specific regulation of different plant processes. The enzymes ADC and ODC can be inhibited by the reversible inhibitors DL- $\alpha-$ difluoromethylarginine (DFMA) and DL- $\alpha-$ difluoromethylornithine (DFMO), respectively. Decarboxylated S adenosylmethionine (DCSAM), which is formed from $S$ adenosylmethionine (SAM) by the enzyme SAM decarboxylase (SAM-DC), can be used as an aminopropyl donor in the conversion of Put to Spd and from Spd to Spm by two reactions catalyzed by two separate and distinct enzymes, Spd synthase and $\mathrm{Spm}$ synthase, respectively. It has been demonstrated that Put and Spd levels inhibit ODC mRNA translation. Methylglyoxal-bisguanylhydrazone (MGBG) and cyclohexylamine are irreversible inhibitors of SAM-DC and Spd synthase activities, respectively. SAM is an important metabolic crossroad since it is also a precursor of ethylene via ACC, in a reaction catalyzed by ACC synthase and finally, ACC is converted to ethylene by ACC oxidase. Furthermore, in some plants, the methyl moiety of SAM can be transferred to Put via Put-N-methyltransferase, to form Nmethyl- Put, which serves as a precursor of nicotine and other alkaloids. As in the case of any plant growth regulators, the intracellular free PA pool does not only depend on its synthesis but also on several other processes including degradation, conjugation, and transport (Valero and Serrano, 2010). 
Effect of exogenously applied polyamines on post-harvest quality and storability of fruits

Given the opposite effects of PAs and ethylene on retarding or accelerating fruit ripening and senescence, respectively, as commented in the previous section, a great deal of research has been focused on the effect of pre- or postharvest PA treatments on fruit quality parameters related to the ripening process. In this sense several experiments have shown that preharvest treatments with PAs during the fruit growing season can decrease ethylene production and delay the ripening process in a wide range of fruit species. However, most of the research about the effect of PAs on fruit ripening has been performed with postharvest treatments and their effects are similar to those of preharvest treatments, thus there is a delay in the postharvest ripening process leading to maintenance of fruit quality attributes. This review comprehensively covers the effect of exogenously applied PAs on maintaining the shelf life of different fruits under postharvest storage conditions.

\section{Apricot}

Apricot fruits treated with putrescine $(1 \mathrm{mM})$ were subjected to mechanical damaged with a $25 \mathrm{~N}$ force and stored at $10^{\circ} \mathrm{C}$. Putrescine treatment improved the shelf life of undamaged and the damaged fruits by reducing weight loss, colour change, ethylene evolution and respiration rates and reduced the bruised zones caused by mechanical damaged (Martinez et al., 2002).

Fruits of two Iranian apricot cultivars ('Lasgerdi' and 'Shahrodi') were immersed in different concentrations of putrescine $(1,2,3$ and $4 \mathrm{mM}$ ) and in distilled water (control) for $5 \mathrm{~min}$ and stored at $4^{\circ} \mathrm{C}(95 \%$ relative humidity). Putrescine @ 4 mM reduced the weight loss and maintained the firmness. Fruits treated with putrescine had lowest total soluble solids, $\mathrm{pH}$ and maturity index while the fruit firmness, titratable acidity, ascorbic acid, total phenolics and antioxidant activity were high. The quality of apricot fruits was improved by the use of putrescine due to its effect on delaying the ripening processes (Davarynejad et al., 2013).

Postharvest application of putrescine or spermidine @1mM in two apricot cultivars 'Bagheri' and 'Asgarabadi' reduced the ethylene production and maintained the firmness and colour of the fruit. Chilling injury incidence was lower in spermidine treated than that of putrescine treated fruits (Koushesh et al., 2012). Similarly, post harvest application of putrescine in apricot 'Tokhm-sefid' resulted in reduction of ethylene production, $\mathrm{SSC}, \mathrm{pH}$ and increase in TA and fruit flesh firmness thus extending the storability (Khosroshahi and Ashari, 2007)

\section{Banana}

The effect of exogenous application of polyamines at varied concentrations viz. PUT $(1 \mathrm{mM}, 3 \mathrm{mM}$ and $6 \mathrm{mM})$ and SPM $(1 \mu \mathrm{M}, 5$ $\mu \mathrm{M}$ and $10 \mu \mathrm{M})$ in improving the quality and storability of banana fruits cv. Grand Naine was examined by Archana and Suresh, 2019.

Among the treatments $5 \mu \mathrm{M}$ spermine was found to be more effective in reducing the physiological loss in weight $(4.06 \%)$, fruit softening $(991.18 \mathrm{~g})$, colour change, delaying the biochemical changes by decreasing the conversion of starch $(3.61 \%)$ into sugars $(16.53 \%)$, and in reducing the consumption of organic acids which was witnessed by low respiration rate $\left(123.84 \mathrm{ml} \quad \mathrm{CO}_{2} / \mathrm{kg} / \mathrm{h}\right)$, highest value for ascorbic acid (13.69 $\mathrm{mg} / 100 \mathrm{~g})$ and titratable acidity $(0.396 \%)$ while maintaining good organoleptic qualities. 
The effect of putrescine on quality and postharvest life of Musa acuminate L. during storage was studied by Hosseini et al., (2016). Fruits were dipped in putrescine solution at different concentrations $(0.5,1$ and $2 \mathrm{mM}$ for $30 \mathrm{~min}$ ) and distilled water as 'control'. Putrescine application maintained firmness, higher levels of TA, ascorbic acid and reduced the loss of weight, sensory acceptability and decay incidence compared to control. Archana et al., (2015) reported that exogenous application of putrescine @ $1 \mathrm{mM}$ for $30 \mathrm{~min}$ in banana fruits cv. Grand Naine reduced the respiration rate, delayed the loss of firmness, peel colour changes and accumulation of total soluble solids content.

\section{Mango}

"Samar Bahisht Chausa" mangos were treated with different concentrations $(0.0,0.1,1.0$ or $2.0 \mathrm{mM}$ ) of putrescine and were made to ripen at $32 \pm 2{ }^{\circ} \mathrm{C}$ for seven days or stored at $11 \pm$ $1^{\circ} \mathrm{C}$ up to 28 days. PUT @ $2.0 \mathrm{mM}$ inhibited ethylene production and suppressed the activities of cell wall enzymes (exopolygalacturonase, endo-polygalacturonase, endo-1,4- $\beta$-d-glucanase ) while resulting in higher phenolics, activity of antioxidative enzymes (CAT, POX and SOD ) and maintained better fruit quality during ripening and cold storage (Razzaq et al., 2014).

Postharvest application of $2 \mathrm{mM}$ spermidine improved the firmness and delayed the deterioration of mango cv. Langra, by suppressing the ethylene production, delaying the chlorophyll decomposition and colour change and through maintaining higher antioxidant and phenolic contents. It also decreased the fungal contamination and increased the shelf life and quality of mango (Zahedi et al., 2019). Fruits of 'Nam Dok Mai No.4' mango were dipped in different concentrations of putrescine $(1,2$ and $4 \mathrm{mmol} / \mathrm{L})$ and then stored at $14^{\circ} \mathrm{C}$. Putrescine
@ 2mmol/L reduced the weight losss, improved superoxide dismutase, catalase, guaiacol peroxidise, ascorbate peroxidise and glutathione reductase activities and total antioxidant content. So, putrescine was found to be effective in prolonging the shelf life (Bussarin and Kanogwan, 2018)

Mango fruits were treated with different concentrations $(0,0.01,0.5,1 \mathrm{mM})$ of polyamines (SPM, SPD and PUT) and stored at $13^{\circ} \mathrm{C}(\mathrm{RH} 85 \pm 5 \%)$. Application of low concentration of SPM $(0.5 \mathrm{mM})$ and higher concentration of PUT $(1 \mathrm{mM})$ or SPD $(1 \mathrm{mM})$ in mango cv. Kensington Pride were found effective in reducing weight loss. SPM was more effective in retarding fruit softening during storage, while PUT was effective in improving fruit quality of ripe fruit. Application of polyamines improved shelf life of mango by retarding fruit softening and colour development during storage and maintained fruit firmness at the ripe stage with increased ascorbic acid content (Malik et al., 2006).

The effect of putrescine at varied concentrations $(0.0,1.0,2.0$ or $3.0 \mathrm{mM})$ on storage life and quality of mango fruits cv. Langra was studied by Jawandha et al., (2012). PUT (2.0 mM) was found to be best concentration which led to reduction in loss of physiological weight and percentage of spoilage and highest palatability rating and provided the good blend of TSS and acidity under storage.

Fruits of mango cv. Dashehari were dipped in putrescine $(0.5$ and $1 \mathrm{mM})$, spermine $(0.5$ and $1 \mathrm{mM})$ and spermidine $(0.5$ and $1 \mathrm{mM})$ for 10 minutes and stored under room and refrigerated conditions. Fruits treated with putrescine $(1.0 \mathrm{mM})$ resulted in the lowest physiological loss in weight while spoilage was significantly reduced to 3.3 percent in mango fruits treated with $0.5 \mathrm{mM}$ putrecine 
compared to 13.3 percent in control after 28 days of storage under refrigerated condition. After four weeks of refrigerated storage chilling injury index was the lowest (0.86) in mango fruits treated with $1 \mathrm{mM}$ putrescine whereas it was highest (4.0) in control. Storage life was extended to 4 weeks in mango fruits treated with $1 \mathrm{mM}$ putricine compared to 2 weeks in control under refrigerated condition (Anju et al., 2014).

The comparative effectiveness of polyamines (PUT, SPD and SPM) was assessed by Chakraborty et al., (2016) in mango cv. Alphonso at concentrations of $0.1 \mathrm{mM}$ and $0.5 \mathrm{mM}$. Fruits dipped in $0.5 \mathrm{mM}$ SPM solution registered least changes in physiochemical properties of mango fruit during the entire storage period. The effectiveness of polyamines to maintain the physiochemical properties of mango were found in the following order SPM $>$ SPD $\geq$ PUT for most the parameters.

\section{Grape}

Bunches of grapes cv. Flame Seedless were dipped in putrescine and spermidine at different concentrations of $0.0,0.5,1.0$ and $1.5 \mathrm{mM}$ and stored at $3-4 \circ \mathrm{C}$ and $90-95 \%$ RH. Putrescine and spermidine at the lowest dose $(0.5 \mathrm{mM})$ was found to be effective in maintaining the berry firmness, peel colour $\left(\mathrm{L}^{*}, \mathrm{C}^{*}, \mathrm{~h}^{\circ}\right.$ ) and stabilized anthocyanins as well as suppressing the pectin methylesterase activity and reducing the rate of electrolyte leakage. The polyamines also retarded the degradation of TSS and TA while maintaining higher total phenol content and reduced decay incidence (Champa et al., 2014).

Application of $1 \mathrm{mM}$ PUT and 1\% Chitosan maintained quality of fresh table grapes (Vitis vinifera) cultivar "Shahroudi" by reducing the weight loss, decay incidence, browning, berry shattering and cracking. Berries treated with polyamines ( 1 and $2 \mathrm{mM}$ ) exhibited higher total phenolic content, catechin, total quercetin and antioxidant activity and lower quercetin 3-galactoside (Shiri et al., 2012)

Pre-harvest foliar spray of putrescine and spermidine $(0,1,2 \mathrm{mM})$ reduced the rate of softening, fungal infection and weight loss during the storage period. The treated fruits showed higher phenolic content, antioxidant activity and anthocyanins (Mirdehghan and Rahimi, 2016).

The exogenous applications of Putrescine @ 2Mm along with Salicylic acid@4mM two times in grape; when berry reached about 4-6 $\mathrm{mm}$ in diameter and at veraison stage reduced cluster weight loss, maintained berry firmness, stabilized berries anthocyanine, reduced juice acidity, berry softening, berries decay and rachis browning during cold storage at $0-2^{\circ} \mathrm{C}$ and $90-95 \%$ RH. It suppressed other ripening related changes as Pectin methylesterase activity. Thus, this treatment can be used commercially maintain quality during cold storage and extend the shelf life of "Flame seedless" grape with acceptable fruit quality (Bassiony et al., 2018).

\section{Pomegranate}

Application of $2 \%$ calcium chloride in combination with $2 \mathrm{mM}$ spermidine significantly reduced chilling injury, browing, water loss, electrolyte and $\mathrm{K}^{+}$leakage and improved the titrable acidity in pomegranate (Ramezanian and Rahemi, 2010)

Combined application of PUT along with carnauba wax enhanced the shelf life of pomegranate fruits by reducing the chilling injury, respiration and ethylene release rate. They maintained the fruit quality by mitigating discoloration, strengthening the firmness of fruit peel without any weight loss 
(Barman et al., 2011). Similarly 2mM putrescine and 1:10 carnauba wax (carnauba wax : water) retained higher anthocyanins, antioxidant, ascorbic acid, tannin and sensory qualities in pomegranate (Barman et al., 2014).

Mirdehghan et al., (2007a) reported that exogenous application of Put or Spd under pressure-infiltration or immersion induced acclimation of pomegranate to low temperature, and in turn protect the fruit from chilling by increasing the levels of endogenous Put and Spd. In addition, the polyamine treatment by reducing the loss of weight and retarded the maturation process by reducing softening and the increasing the ratio SSC/acidity.

Thus, storability and shelf-life could be extended in pomegranate stored at low temperatures that usually develop CI. Pressure-infiltration of polyamines seems to be the best tool to increase the endogenous polyamines, although immersion also imparted beneficial effects which could be attributed to the waxy nature of pomegranate skin. Similarly, in a study by Mirdehghan et al., (2007b) pomegranate fruits treated with putrescine (Put) or spermidine (Spd) at $1 \mathrm{mM}$ were found to be effective in maintaining higher concentration of ascorbic acid, total phenolic compounds, and total anthocyanins in arils.

\section{Plum}

Four plum cultivars ("Santa Rosa", "Black Star", "Black Diamond" and "Golden Japan") when exogenously treated with PUT $(1 \mathrm{mM})$ followed by their storage at $20{ }^{\circ} \mathrm{C}$ resulted in enhancement of shelf life and improved quality attributes of fruits with higher fruit and flesh firmness, lower soluble solids concentration and titratable acidity evolution, reduced weight loss and delayed colour changes (Serrano et al., 2003). Khan et al., (2008) reported that pre-harvest spray application of PUT @ $2.0 \mathrm{mmol} \mathrm{L}{ }^{-1}$, one week before anticipated commercial harvest was effective in delaying the fruit ripening process with acceptable fruit quality during ripening at ambient temperature or to extend the storage life at $0 \pm 1{ }^{\circ} \mathrm{C}$ of plum up to 6 weeks with minimum losses of fruit quality.

Pre- and post-harvest application of PUT (0.1, 1.0 or $2.0 \mathrm{mM}$ ) to "Angelino" plums resulted in delayed fruit ripening under storage $(0 \pm 1$ $\left.{ }^{\circ} \mathrm{C}, 90 \pm 5 \% \mathrm{RH}\right)$ by reducing the ethylene production and activities of fruit softening enzyme (exopolygalacturonase, endo polygalacturonase, pectin esterase and endo$1,4-\beta$-D-glucanase) in skin and pulp tissues during storage (Khan et al., 2007).

The effect of putrescine during the postharvest storage period of mechanically damaged "Blackstar" plums was investigated by Vicente et al., (2002). Putrescine (1mM) reduced the mechanical damage and flesh deformation. The accumulation of cell wall conjugated PUT and SPD was observed in plums for two weeks under storage. Enhanced levels of bounded PAs contributed to the high level of firmness. Besides this, during initial seven days of storage, damaged control plums showed higher levels of free SPD and were considered a physiological marker for stress induced by mechanical damage.

\section{Citrus}

Raeisi et al., (2013) investigated the effect of spermidine at various concentrations $(0,1$ and $1.5 \mathrm{mM}$ ) on Valencia orange var. olinda. They found that spermidine @1.5 mM was effective in reducing the chilling injury and improving the quality of fruits.

Valero et al., (1998) reported that vacuum infiltration with $1 \mathrm{mM}$ putrescine was more 
effective than that with calcium to retard the senescence process of the lemon fruit at the early ripening stage, which induced increased fruit firmness and lowered weight loss. Both treatments delayed the colour change, which could be related to the lower levels of ABA during storage. Post- harvest application of putrescine and calcium (at $1 \mathrm{mM}$ ) in lemon maintained higher firmness values and more resistance to peel rupture during storage at 15 ${ }^{\circ} \mathrm{C}$. Treated lemons showed also less deformation when the compression force (50 $\mathrm{N})$ was applied to induce mechanical damage (Martinez et al., 1999).

'Lisbon' lemons were vacuum infiltrated with putrescine or spermidine @ $1 \mathrm{mM}$ at $15^{\circ} \mathrm{C}$ with $-33 \mathrm{kPa}$ for $10 \mathrm{~min}$ prior to cold storage. Untreated and spermidine treated fruits developed the symptoms of chilling injury such as peel pitting, electrolyte leakage after 2 weeks of storage, whereas these changes were reduced in putrescine treated fruits up to 6 weeks. Both the polyamines were found to be effcetive in maintain the firmness upto 4 weeks, but putrescine was found to be superior than spermidine (Safizadeh, 2013).

\section{Peach}

Peaches treated with putrescine $(1 \mathrm{mM})$ and $\mathrm{GA}_{3}$ (100 mg L-1) maintained higher fruit firmness during storage, and the respiration rate and ethylene emission were reduced compared with control peaches. In addition, the treatments were also effective in reducing the susceptibility of the fruits to be mechanically damaged (Martinez et al., 2000).

Peach fruits treated with PUT (1 $\mathrm{mM})$ alone or in combination with ultrasound $(32 \mathrm{kHz}$ at $60 \mathrm{~W} / \mathrm{L}, 10 \mathrm{~m}$ ) improved peach quality and storability by inhibiting the respiration rate, delaying the process of ripening and improving the firmness.
It also reduced symptoms of browning and leatheriness as compared to control fruits after three weeks under storage (Bal, 2013).

\section{Other fruit crops}

Kiwifruits immersed in different concentrations of spermine $[(0.5,1.0$ and 1.5$)$ $\mathrm{mM}]$ and spermidine $[(1.0,1.5$ and 2.0$) \mathrm{mM}]$ showed reduced amount of ethylene evolution, polygalacturonase and lipoxygenase activities and lower respiration rate when compared to control. The doses of spermine at $1.5 \mathrm{mM}$ and spermidine at 2.0 $\mathrm{mM}$ were found to be best in extending the shelf life of kiwifruits (Jhalegar et al., 2012). Pressure infiltration of polyamines retarded fruit ripening, inhibited ethylene production and reduced respiration in kiwi fruit (Petkou et al., 2004).

Jiang and Chen (1995) recommended polyamines for the retention of red colour in litchi at low temperature storage for 30 days. Polyamines such as putrescine, spermine or spermidine $(1 \mathrm{mmol} / \mathrm{l})$ in combination with fungicides were reported to reduce ethylene production, POD activity and also retain membrane integrity. Among the polyamines tested, spermine was the most effective.

Hosseini et al., (2017) reported that preharvest application of 1 and $2 \mathrm{mM}$ putrescine maintained the postharvest life of pear cv. Spadona by reducing weight loss, fruit softening, color changes as well as retarding the degradation rate of TSS, TA, $\mathrm{pH}$, vitamin $\mathrm{C}$, total phenol and total antioxidant in pear fruit during storage.

Moreover, the storage life and marketability of putrescine treated fruits were prolonged by decreasing decay incidence. Thus, pre-harvest application of putrescine can be an effective means for extending the postharvest life of pear cv. Spadona. 
The immersion of strawberry cv. "Selva" in putrescine at different concentrations (0.3, $0.5,1$ or $2 \mathrm{mM}$ ) led to decreased ethylene production and improved the appearance of fruit by increasing the firmness when stored at $5{ }^{\circ} \mathrm{C}$. Fruits immerged in putrescine @ 1and $2 \mathrm{mM}$ had shelf life upto 12 and 14 days whereas the control fruits had 8 days of storage life (Khosroshahi et al., 2007). Vacuum infiltration of polyamines improved thefirmness of strawberry slices when stored at $1{ }^{\circ} \mathrm{C}$ (Ponappa et al., 1993)

Preharvest foliar spray of putrscine and spermidine $(0,1,2 \mathrm{mM})$ to pistachio tree, 'Kalleh Ghochi' and 'Fandoghi' 20 to 35 days before harvest improved the pistachio storability by delaying the softening and decreasing the weight loss and fungal infection when stored at $1.5 \pm 1{ }^{\circ} \mathrm{C}$ and 90 95\% relative humidity (Mirdehghan et al., 2012).

Jamun is underutilized minor fruit, which is seasonal and highly perishable with short shelf life. To improve the storage period, the fruits were treated with $1 \mathrm{mM}$ putrescine for 5 min. The treated fruits registered lower respiration rates and higher firmness, delayed the physiochemical and physiological changes in jamun fruits under ambient storage (Archana et al., 2015).

These results provide an evidence for the numerous beneficial effects of the exogenous PA treatments, at pre- and postharvest time in delaying the postharvest ripening and senescence processes by extending the shelf life of fruits and enhancing the fruit quality attributes. Polyamines are also effective on increasing the activity of several antioxidant enzymes, such as SOD, CAT, POD, and APX. Nevertheless, the precise physiological and molecular mechanisms by which polyamines increase both antioxidant systems remain elusive and deserve further research.

\section{References}

Anju, B., Raj, K.K., Monica, R. and Neeraj, G. 2014. Effect of polyamines on shelf life and chilling injury of mango cv. Dashehari. The Bioscan. 9(3): 10971100.

Archana, T.J. and Suresh, G.J. 2019. Putrescine and Spermine Affects the Postharvest Storage Potential of Banana Cv. Grand Naine. International Journal of Current Microbiology and Applied Sciences. 8(01): 3127-3137.

Archana, T.J., Suresha, G.J. and Swamy, G.S.K. 2015. Influence of Exogenous Application of Putrescine on Ripening Changes in Banana cv. Grand Naine. International. J. Food. Ferment. Technol. 5(1), 53-58.

Archana, T.J., Suresha, G.J., Vandana, A.K. and Swamy, G.S.K. 2015. Effect of exogenous application of putrescine on storage behaviour of jamun (Syzygium cumini Skeels) fruits. III International Symposium on underutilized plant species. 1241, 577-582.

Bal, E. Effects of exogenous polyamine and ultrasound treatment to improve peach storability. Chilean Journal of Agricultural Research. 2013, 73, 435440.

Barman, K., Asrey, R. and Pal, R.K. 2011. Putrescine and carnauba wax pretreatments alleviate chilling injury, enhance shelf life and preserve pomegranate fruit quality during cold storage. Sci. Hort. 2011, 130, 795-800.

Barman, K., Asrey, R., Pal, R.K., Charanjit, K. and Jha, S.K. 2014. Influence of putrescine and carnauba wax on functional and sensory quality of pomegranate (Punica granatum L. fruits during storage. Journal of Food Science and Technology. 51, 111-117.

Bassiony, S.S., Maha, H., Abd, E.A. and Hayam, M.F. 2018. Effect of foliar 
application of putrescine and salicylic acid on yield, fruit quality and storability of "Flame Seedless" Grape (Vitis vinifera L.). J. Plant Production, Mansoura Univ. 9 (12): 1203 - 1214.

Bouchereau, A., Aziz, A., Larher, F., and Martin, T.J. 1999. Polyamines and environmental challenges: recent development. Plant Sci. 140: 103-125.

Bussarin, W. and Kanogwan, S. 2018. Effects of putrescine treatment on the quality attributes and antioxidant activities of 'Nam Dok Mai No.4' mango fruit during storage. Scientia Horticulturae. 233:22-28

Cai, Q. 2009. Progress in physiology of plant polyamines. Fujian Sci. Technol. Rice Wheat. 27, 37-40.

Chakraborty, B., Rajendra, K.P.B., Yogesh, V.N. and Mangaldeep, S. 2016. Exogenous application of polyamines maintains physico-chemical properties of mango (Mangifera indica L.) cv.Alphonso under aimbient storage. Environment and ecology. 35(2): 763767.

Champa, H.W.A., Gill, M.I.S., Mahajan, B.V.C. and Arora, N.K. Postharvest treatment of polyamines maintains quality and extends shelf life of table grapes (Vitis vinifera L.) cv. Flame Seedless. Postharvest Biology and Technology. 2014, 91, 57-63.

Chen, D., Shao, Q., Yin, L., Younis, A. and Zheng B. 2019. Polyamine Function in Plants: Metabolism, Regulation on Development, and Roles in Abiotic Stress Responses. Front. Plant Sci. 9:1945.

Davarynejad, G., Zarei, M., Ardakani, E. and Nasrabadi, M.E. 2013. Influence of putrescine application on storability, postharvest quality and antioxidant activity of two Iranian apricot (Prunus armeniaca L.) cultivars. Notulae Scientia Biologicae. 5(2), 212-219.
Duan, G. 2000. Effect of speridine on protein contents and protease during senescence of fxicsed wheat leaves. J. Sichuan Teach. Coll. 21, 44-47.

Evans, P.T. and Malmberg, R.L. 1989. Do polyamines have roles in plant development? Annu. Rev. Plant Physiol. Plant Mol. Biol., 40: 235-269.

Galston, A.W., Sawhney, R.K. 1990. Polyamines in plant physiology. Plant Physiol. 94:406-410.

Hosseini, M.S., Fakhar, Z., Babalar, M. and Askari, M.A. 2017. Effect of preharvest putrescine treatment on quality and postharvest life of pear cv. Spadona. Adv. Hort. Sci. 31(1): 11-17.

Hosseini, M.S., Zahedi, S.M. and Fakhar, Z. 2016. Pre-storage putrescine treatment maintains quality and prolongs postharvest life of Musa acuminata L. Adv. Hort. Sci. 30(3): 159-164.

Jawandha, S.K., Gill, M.S., Singh, N., Gill, P.P.S. and Singh, N. 2012. Effect of postharvest treatments of putrescine on storage of mango cv. Langra. Afr. J. Agric. Res. 7, 6432-6436.

Jhalegar, M.J., Sharma, R.R., Pal, R.K. and Rana, V. 2012. Effect of postharvest treatments with polyamines on physiological and biochemical attributes of kiwifruit (Actinidia deliciosa) cv. Allison. Fruits. 67, 13-22.

Jiang, Y.M. and Chen, F. 1995. A study on polyamine change and browning of fruit during cold storage of litchi (Litchi chinensis Sonn.). Postharvest Biology and Technology 5, 245-250.

Khan, A.S., Singh, Z. and Abbasi, N.A. 2007. Pre-storage putrescine application suppresses ethylene biosynthesis and retards fruit softening during low temperature storage in 'Angelino' plum. Postharv. Biol. Technol. 46, 36-46.

Khan, A.S., Singh, Z., Abbasi, N.A. and Ewald, S. 2008. Pre- or post-harvest applications of 
Khosroshahi, M. R.Z., Esna-Ashari, M. and Ershadi, A. 2007. Effect of exogenous putrescine on post-harvest life of strawberry (Fragaria ananassa Duch.) fruit, cultivar Selva. Scientia Horticultuare, 114, 27-32.

Khosroshahi, M.R.Z. and Ashari, M.E. 2007. Postharvest putrescine treatments extend the storage life of apricot (Prunus armeniaca L.) 'Tokhm-sefid' fruit. The Journal of Horticultural Science and Biotechnology. 82(6), 986990.

Koushesh, S.M., Arzani, K. and Barzegar, M. 2012. Postharvest polyamine application alleviates chilling injury and affects apricot storage ability. Journal of Agriculture and Food Chemistry. 60, 8947-8953.

Malik, A.U., Singh, Z. and Tan, S.C. 2006. Exogenous application of polyamines improves shelf life and fruit quality of mango. Acta Hortic. 699, 291-296

Martinez, R.D., Serrano, M., Carbonell, A., Burgos, L., Riquelme, F. and Valero, D. 2002. Effects of postharvest putrescine treatment on extending shelf life and reducing mechanical damage in apricot. Journal of Food Science. 67(5), 17061712.

Martinez, R.D., Valero, D., Serrano, M., Burlo, M., Carbonell, A., Burgos, L. and Requelme, F. 2000. Exogenous polyamine and gibberellic acid effects on peach (Prunus persica L.) storability improvement. Journal of Food Science. 65, 288-294.

Martinez, R.D., Valero, D., Serrano, M., Martinez, S.F. and Riquelme F. 1999. Effects of post harvest putrescine and calcium treatments on reducing mechanical damage and polyamines and abscisic acid levels during lemon storage. Journal of the Science of Food and Agriculture 79, 1589-1595.

Mirdehghan, S.H. and Rahimi, S. 2016. Pre- harvest application of polyamines enhances antioxidants and table grape (Vitis vinifera L.) quality during postharvest period. Food Chemistry, 196, 1040-1047.

Mirdehghan, S.H., Khanamani, Z., Shamshiri, M.H. and Hokmabadi. 2012. Preharvest foliar application of putrescine and spermine on postharvest quality of free pistachio. Acta Horti. 299-303

Mirdehghan, S.H., Rahemi, M., Castillo, S., Martinez, R., Maria, S.D. and Valero, D. 2007a. Pre- storage application of polyamines by pressure immersion improves shelf life of pomegranate stored at chilling temperateure by increasing endogenous polyamine levels. Postharvest Biology and Technology. 44, 26-33.

Mirdehghan, S.H., Rahemi, M., Serrano, M.F., Domingo, M.R. and Valero, D. 2007b. The application of polyamines by pressure or immersion as a tool to maintain fuctional properties in stored pomegranate arils. Journal of Agriculture and Food Chemistry 55, 755-760.

Petkou, I.T., Pritsa, T.S. and Sfakiotakis, E.M. 2004. Effects of polyamines on ethylene production, respiration and ripening of kiwifruit. Journal of Horticultural Science and Biotechnology. 79, 977-980.

Ponappa, T., Scheerens, J.C. and Miller, A.R. 1993. Vacuum infiltration of polyamines increases firmness of strawberry slices under various storage conditions. J. Food Sci. 58, 361-364.

putrescine and low temperature storage affect fruit ripening and quality of 'Angelino' plum. Journal of the Science of Food and Agriculture. 88, 1686-1695.

Raeisi, M., Samani, R.B. and Honarvar, M. 2013. Application of exogenous spermidine treatment for reducing of chilling on fruit quality and quantity of 
Valencia orange var. Olinda. Int. J. Farm. Allied Sci. 2, 1292-1297.

Ramezanian, A. and Rahemi, M. 2010. Effect of pre-storage application of spermidine, calcium chloride and hot water on chilling injury of cold stored pomegranate. Acta Hortic. 877, 491498

Razzaq, K., Khan, A.S., Malik, A.U., Shahid, M. and Ullah, S. 2014. Role of putrescine in regulating fruit softening and antioxidative enzyme systems in 'Samar Bahisht Chaunsa' mango. Postharv. Biol. Technol. 96, 23-32.

Safizadeh, M.R. 2013. Vaccum infiltration of polyamines reduces chilling injury and firmness loss of lemon stored at chilling temperature. International Journal of Agriculture and Crop Sciences. 6(8): 445-451.

Serrano, M., Romero, D.M., Guillen, F. and Valero, D. 2003. Effects of exogenous putrescine on improving shelf life of four plum cultivars. Postharv. Biol. Technol. 30, 259-271.

Shiri, M., Ghasemnezhad, A., Bakhshi Davood, M., Sarikhani, H. 2012. Effect of postharvest putrescine application and chitosan coating on maintaining quality of table grape cv. Shahroudi during long term storage. J. Food Process. Pres. 37: 999-1007
Valero, D. and Serrano, M. 2010. Postharvest biology and technology for preserving fruit quality. CRC/Taylor \& Francis, Boca Raton

Valero, D., Martinez, R.D. and Serrano, M. 2002. The role of polyamines in the improvement of the shelf life of fruit. Trends Food Sci. Technol. 13: 228-234.

Valero, D., Martinez, R.D., Serrano, M. and Riquelme, F., 1998. Influence of postharvest treatment with putrescine and calcium on endogenous polyamines, firmness and abscisic acid in lemon (Citrus lemon L. Burm cv. Verna). J. Agric. Food Chem. 46, 21022109.

Vicente, A.P., Martinez, R.D., Carbonell, A., Serrano, M., Requelme, F., Guillen, F. and Valero, D. 2002. Role of polyamines on extending shelf life and the reduction of mechanical damage during plum (Prunus salicina Lindl.) storage. Postharvest Biol. Technol. 25, 25-32.

Zahedi, S.M., Hosseini, M.S., Karimi, M. and Ebrahimzadeh, A. 2019. Effects of postharvest polyamine application and edible coating on maintaining quality of mango (Mangifera indica L.) cv. Langra during cold storage. Food Science and Nutrition.7:433-441.

\section{How to cite this article:}

Divya Vani Vaka, Kommana Pavani, Bharathi Nirujogi and Vinaya Kumar Reddy, P. 2020. Role of Polyamines on Post-Harvest Fruit Quality and Storability. Int.J.Curr.Microbiol.App.Sci. 9(06): 3519-3529. doi: https://doi.org/10.20546/ijcmas.2020.906.414 